\title{
Redesign Kerangka Box Body Mobil Pickup Multiguna Pedesaan Berbasis Metode Elemen Hingga
}

\author{
Lina Damayanti dan Julendra Bambang Ariatedja \\ Departemen Teknik Mesin, Fakultas Teknologi Industri, Institut Teknologi Sepuluh Nopember (ITS) \\ e-mail: ariatedja@me.its.ac.id
}

\begin{abstract}
Abstrak-Mobil pickup multiguna pedesaan adalah sebuah mobil pickup yang digabungkan dengan box yang dapat dilepas atau pasang sesuai kebutuhan. Penggunaan box khususnya untuk kegiatan berniaga kurang maksimal, dengan ruang yang tidak terlalu besar membuat penjual membatasi barang yang akan dijajakan, sehingga perlu adanya redesign agar lebih fungsional untuk kegiatan berniaga. Selain itu massa total box yang masih dapat dikurangi dengan pemilihan material yang lebih ringan seperti polycarbonathe. Untuk melakukan redesign box mobil ini, pertama merancang box body dengan menggunakan software solid modeling. Selanjutnya adalah perhitungan beban yang meliputi beban akselerasi, pengereman dan belok. Simulasi dengan metode elemen hingga menggunakan software ANSYS 19.1 dilakukan kemudian. Pengujian ini diakhiri dengan memperoleh data hasil simulasi berupa tegangan von Mises, deformasi total dan safety factor, kemudian mengevaluasi hasil yang diperoleh. Hasil simulasi didapatkan penurunan massa box sebesar 8,65\%. Saat mobil pickup multiguna pedesaan mengalami efek percepatan pada lintasan datar diperoleh nilai von Mises stress maksimum yang terjadi sebesar $87,346 \mathrm{MPa}$, nilai total deformation maksimum sebesar $5,35 \mathrm{~mm}$ dengan safety factor 3,034. Sebaliknya saat pengereman nilai von Mises stress maksimum yang terjadi sebesar 81,671 MPa, nilai total deformation maksimum sebesar $5,56 \mathrm{~mm}$ dengan safety factor 7,02. Saat melewati lintasan belok nilai von Mises stress maksimum yang terjadi sebesar 26,04 Mpa, nilai total deformation maksimum sebesar $1,63 \mathrm{~mm}$ dengan safety factor 3,28. Dari analisis dan verifikasi hasil uji terhadap persyaratan desain, box body memenuhi kelayakan keamanan.
\end{abstract}

Kata Kunci-Struktur Box Body Mobil, Tegangan Von Mises, Deformasi Total, Metode Elemen Hingga.

\section{PENDAHULUAN}

$\mathrm{P}$ EMBUATAN prototype box yang pertama menggunakan material mild steel dengan massa total box body sebesar $700 \mathrm{~kg}$. Massa tersebut menjadi bahan evaluasi karena mesin yang digunakan pada mobil tidak besar, $650 \mathrm{cc}$, sehingga untuk menunjukkan performa kerja yang baik dibutuhkan beban body yang ringan baik pada body mobil maupun box body. Hal inilah yang menjadi alasan dilakukan pengembangan desain yang kedua pada tahun 2017 terhadap prototype box. Hal ini bertujuan untuk menurunkan massa box. Pada desain kedua ini material diganti menggunakan komposit fiber glass di bagian lapisan terluar saja. Sehingga massa total box body menjadi 415 $\mathrm{kg}$.
Box mobil pickup multiguna pedesaan ini dapat dilepas atau pasang sesuai kebutuhan. Jika ingin mengangkut hasil panen dan mesin penggiling padi, maka box mobil akan dilepas. Sebaliknya jika untuk mengangkut penumpang dan kegiatan berniaga maka box ini akan dipasang. Penggunaan box khususnya untuk kegiatan berniaga maka bagian jendela akan dibuka seperti pada Gambar 1, dengan ruang yang seperti itu membuat penjual membatasi barang yang akan dijajakan,



Perancangan struktur bodi terus dikembangkan seiring berjalannya waktu. Pada tahun 1970-an perancangan struktur bodi dilakukan menggunakan analisis modern berbasis komputer dengan menggunakan metode elemen hingga. Kemudian pada tahun 1985 dikembangkan struktur bodi dengan ukuran yang lebih kecil oleh negara Amerika Serikat guna menurunkan konsumsi bahan bakar [1].

Untuk material yang awalnya berbahan plain carbon steel menjadi bahan polycarbonate. Pemakaian bahan polycarbonate bisa mendatangakan beberapa keuntungan. Antara lain yaitu bahan yang digunakan untuk membuatnya bersifat ringan namun punya sifat yang kuat dan kokoh, jadi sangat aman untuk diaplikasikan di mana saja. Proses pemasangan juga sangat sederhana dan cepat, tidak membutuhkan waktu yang lama, terlebih dibanding dengan pemasangan bahan atap biasa [2].

Gaya-gaya yang terjadi pada kendaraan berupa gaya dinamis atau beban dinamis. Untuk mempermudah dalam analisis permodelan, gaya-gaya dinamis tersebut digantikan dengan gaya- gaya statis (beban statis) yang terjadi pada kendaraan dikalikan dengan faktor beban dinamis. Faktor beban dinamis yang digunakan pada pembebanan ini adalah 2,5 hingga 3,0 untuk kendaraan komersial dan 4 untuk kendaraan off-road atau cross-country [3]. 
Teori yang diakui paling sederhana ini dikemukakan oleh William John Macquorn Rankine (1802-1872), sehingga teori ini sering disebut dengan teori kegagalan Rankine. Teori ini cocok digunakan untuk analisis pada material getas (brittle). Kegagalan suatu material terjadi bila tegangan normal maksimum mencapai suatu harga tegangan luluh (yield) atau tegangan patahnya (fracture), tanpa memperhatikan tegangan utama (principal stress) lainnya [4].

Tahap-tahap dasar dalam finite element analysis adalah pre-processing, yaitu melakukan diskretisasi model menjadi elemen-elemen hingga, dalam bentuk nodal-nodal dan elemenelemen. Selanjutnya menggabungkan elemen-elemen lokal menjadi solusi global, dan membentuk matriks kekakuan global sekaligus mengaplikasikan kondisi batas, kondisi awal, dan beban-beban yang terjadi. Tahap kedua adalah processing atau solving, dimana komputer menyelesaikan sejumlah perhitungan aljabar linier atau non linier sesuai kondisi yang diterapkan pada tahap pre-processing. Kemudian tahap terakhir adalah post processing, yaitu mengorganisasi dan mengintepretasi data hasil perhitungan yang berupa gambar, kurva atau animasi. Untuk melakukan simulasi ini menggunakan software ANSYS 19.1 [5].

\section{METODE PENELITIAN}

\section{A. Model Struktur}

Pemodelan gambar dengan konsep rancangan yang telah dibuat. Gambar terdiri dari bagian kerangka yang ditunjukkan pada Gambar 2 dan bagian body box pada Gambar 3, lalu di assembly menggunakan software yang sama.

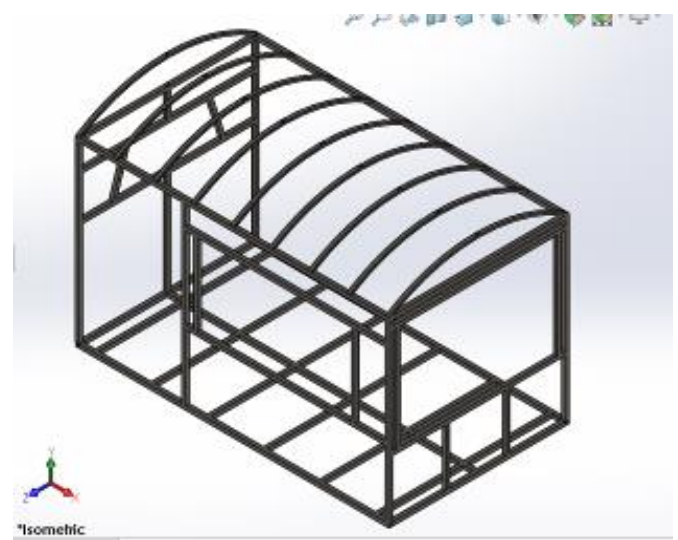

Gambar 2. Kerangka box mobil pickup multiguna pedesaan.

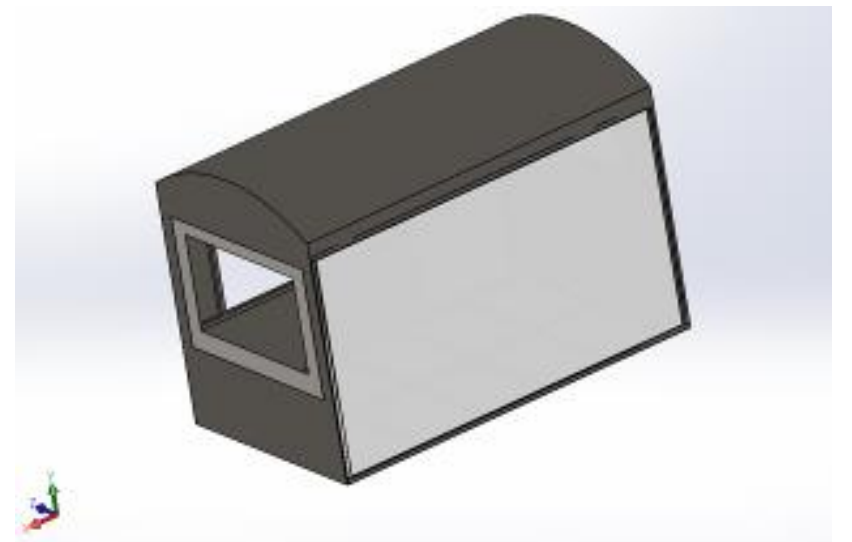

Gambar 3. Model assembly box mobil pickup.

\section{B. Sifat Material}

Pada model digunakan 3 material yang berbeda yaitu ASTM A360 steel, plain carbon steel dan polycarbonate. Seperti pada Tabel 1 dibawah ini.

Tabel 1.

Sifat material [6].

\begin{tabular}{|c|c|c|c|c|}
\hline Objek & Material & $\begin{array}{l}\text { Massa } \\
\text { jenis }\end{array}$ & $\begin{array}{l}\text { Tensile } \\
\text { yield } \\
\text { strength }\end{array}$ & $\begin{array}{l}\text { Tensile } \\
\text { ultimate } \\
\text { strength }\end{array}$ \\
\hline Kerangka & $\begin{array}{l}\text { ASTM A36 } \\
\text { Steel }\end{array}$ & $\begin{array}{l}7850 \\
\mathrm{~kg} / \mathrm{m}^{3}\end{array}$ & $250 \mathrm{Mpa}$ & $415 \mathrm{Mpa}$ \\
\hline $\begin{array}{l}\text { Alas dan } \\
\text { Pintu }\end{array}$ & $\begin{array}{l}\text { Plain } \\
\text { Carbon } \\
\text { Steel }\end{array}$ & $\begin{array}{l}7800 \\
\mathrm{~kg} / \mathrm{m}^{3}\end{array}$ & $\begin{array}{l}220,594 \\
\text { Мpa }\end{array}$ & $399,826 \mathrm{MPa}$ \\
\hline Box & $\begin{array}{l}\text { Polycar- } \\
\text { bonate }\end{array}$ & $\begin{array}{l}1200 \\
\mathrm{~kg} / \mathrm{m}^{3}\end{array}$ & $69,7 \mathrm{MPa}$ & $64 \mathrm{MPa}$ \\
\hline
\end{tabular}

\section{Meshing}

Jenis elemen meshing yang diaplikasikan pada struktur box dengan nilai element size sebesar $11 \mathrm{~mm}$

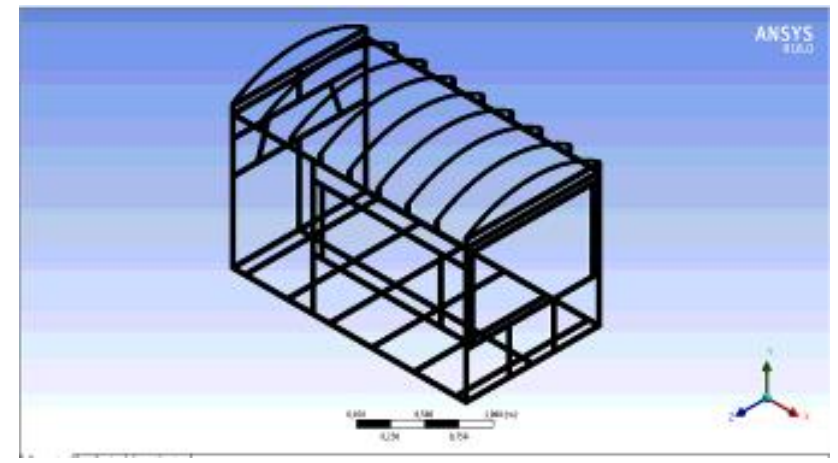

Gambar 4 Hasil meshing pada kerangka box body. 


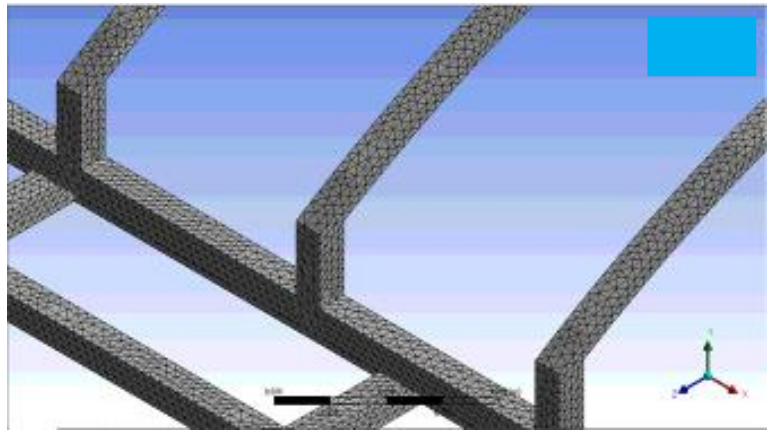

Gambar 5.Gambar detail hasil meshing.

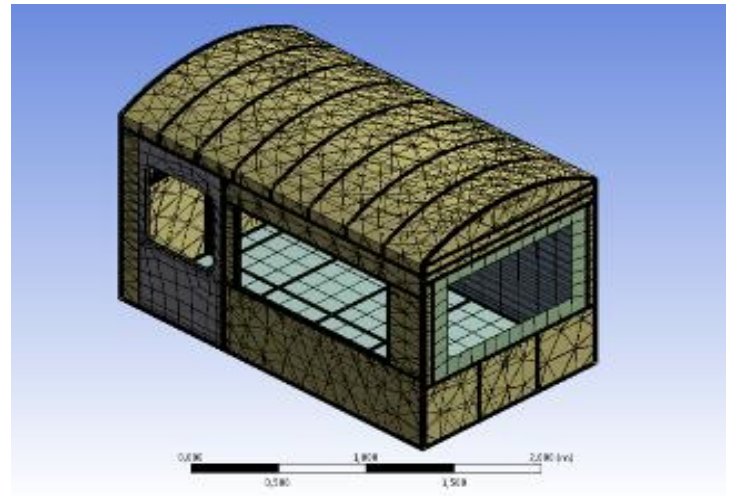

Gambar 6. Hasil meshing untuk box bodi.

Gambar 4 menunjukkan hasil meshing pada kerangka dan Gambar 6 menunjukkan hasil meshing untuk box bodi. Untuk detail meshing dapat terlihat pada gambar 4.

\section{Pembebanan dan Boundary Condition}

Boundary condition (kondisi batas) adalah inputan awal dari simulasi untuk inisiasi pada perhitungan selanjutnya. Kondisi batas adalah pin support yang berasal dari sistem clamping dan displacement pada permukaan bawah box seperti Gambar 7.

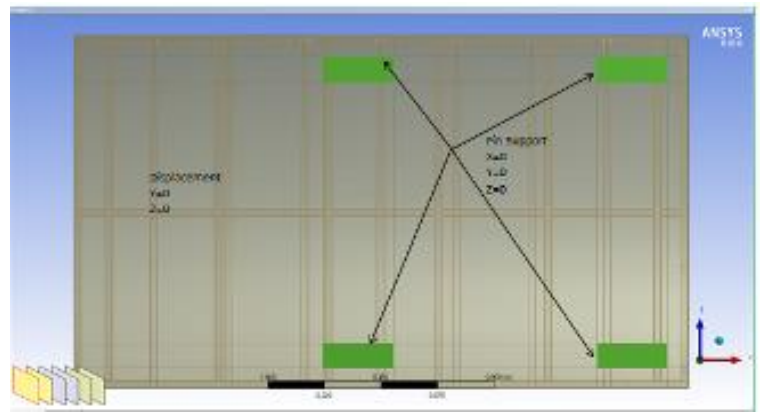

Gambar 7. Posisi kondisi batas.

Pembebanan didapat dari gaya inersia akibat akselerasi maupun pengereman dan berat muatan seperti Gambar 8 . Dengan massa box sebesar 379,09 kg, massa muatan $2000 \mathrm{~kg}$, percepatan dan pengeraman $7,5375 \mathrm{~m} / \mathrm{s}^{2}$ dan percepatan sentripetal $3,133 \mathrm{~m} / \mathrm{s}^{2}$,Perhitungan dilakukan menggunakan rumus Newton.

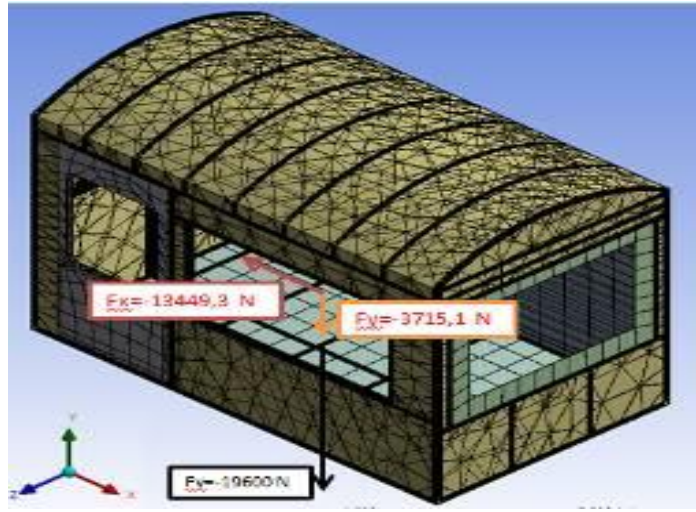

Gambar 8.Penempatan pembebanan pada box body

\section{HASIL DAN ANALISA}

A. Model Box

Tabel 2

Bagian-bagian pada box mobil.

\begin{tabular}{llll}
\hline \hline No & Nama & Bahan & Massa $(\mathrm{kg})$ \\
\hline 1 & Rangka box & ASTM A36 Steel & 143,89 \\
2 & Rangka pintu & ASTM A36 Steel & 5,7481 \\
3 & Lapisan dalam & Plain carbon steel & 80,294 \\
4 & Alas & Plain carbon steel & 80,294 \\
5 & Pintu dalam & Plain carbon steel & 8,5277 \\
6 & Pintu luar & Plain carbon steel & 13,332 \\
7 & Lapisan luar & Polycarbonate & 34,05 \\
8 & Jendela belakang & Polycarbonate & 1,3975 \\
9 & Penutup samping & Polycarbonate & 11,603 \\
& & Massa total & 379,09 \\
\hline \hline
\end{tabular}

Massa total untuk redesign body box dapat dilihat pada Tabel 2 sebesar 379,09 kg. Sedangkan massa box body kedua sebesar $415 \mathrm{~kg}$. Dengan pergantian material di beberapa bagian ini mengakibatkan penurunan massa. Penurunan massa yang terjadi yaitu sebesar $8,65 \%$. Tabel 3 menunjukkan detail komponen yang mengalami perubahan

Tabel 3.

Perbedaan prototype box kedua dengan hasil redesign.

\begin{tabular}{ccccc}
\hline \hline Nama & $\begin{array}{c}\text { Massa } \\
\text { awal }(\mathrm{kg})\end{array}$ & $\begin{array}{c}\text { Massa } \\
\text { redesign } \\
(\mathrm{kg})\end{array}$ & $\begin{array}{c}\text { Perbedaan } \\
(\%)\end{array}$ & Keterangan \\
\hline Rangka box & 162.56 & 143.89 & 11,48 & $\mathrm{~m}_{\text {awal }}>\mathrm{m}_{\text {redesign }}$ \\
Lapisan luar & 51.648 & 34.05 & 34,07 & $\mathrm{~m}_{\text {awal }}>\mathrm{m}_{\text {redesign }}$ \\
Penutup & 10.172 & 11.60 & 12,31 & $\mathrm{~m}_{\text {awal }}<\mathrm{m}_{\text {redesign }}$ \\
Samping & & & & \\
\hline \hline
\end{tabular}

a. Saat Mobil Mengalami Percepatan

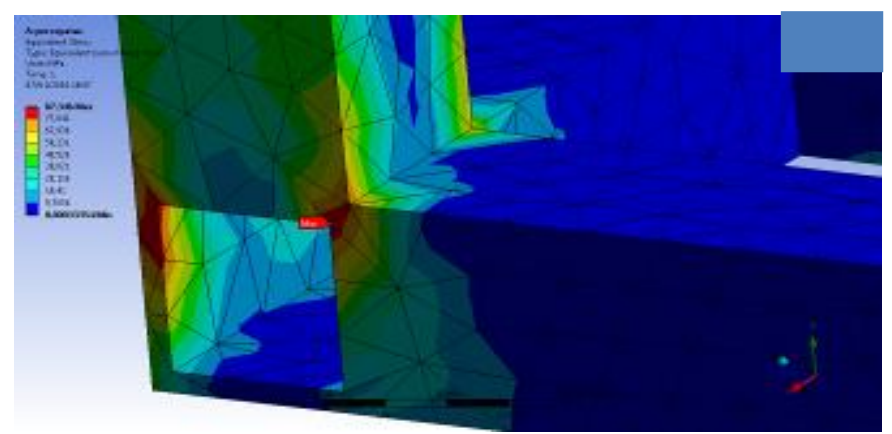

Gambar 9. Detail area yang mengalami stress maksimal pada kerangka. 
Gambar 9 merupakan letak tegangan maksimal pada kerangka box dengan nilai tegangan von-Mises maksimum sebesar 87,346 MPa.

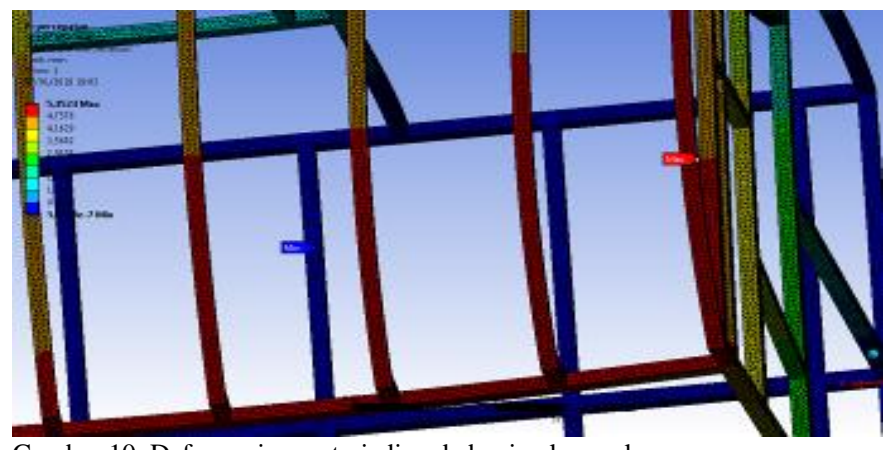

Gambar 10. Deformasi yang terjadi pada bagian kerangka.

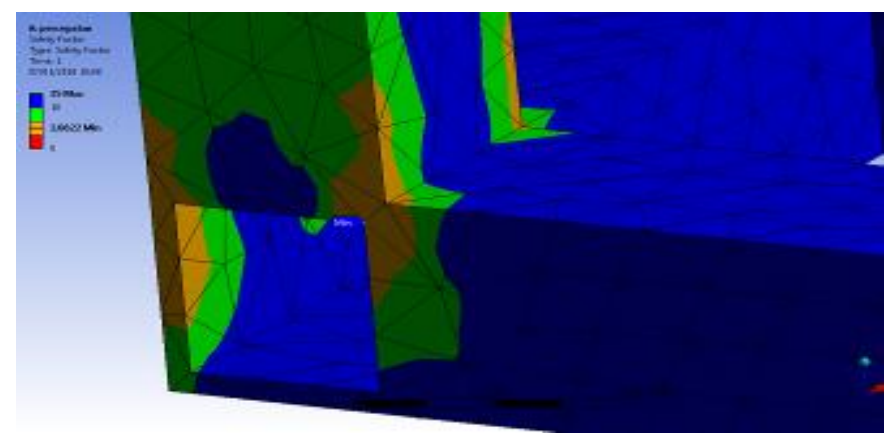

Gambar 11. Safety factor hasil simulasi efek percepatan.

Perubahan bentuk maksimal yang terjadi pada struktur rangka box adalah sebesar $5,35 \mathrm{~mm}$ dari bentuk awalnya yang ditunjukkan pada daerah berwarna merah pada Gambar 10.

Nilai safety factor maksimum dari hasil simulasi adalah 15 dan minimum 3,034 ditunjukkan pada Gambar 11.

b. Saat Mobil Mengalami Pengereman

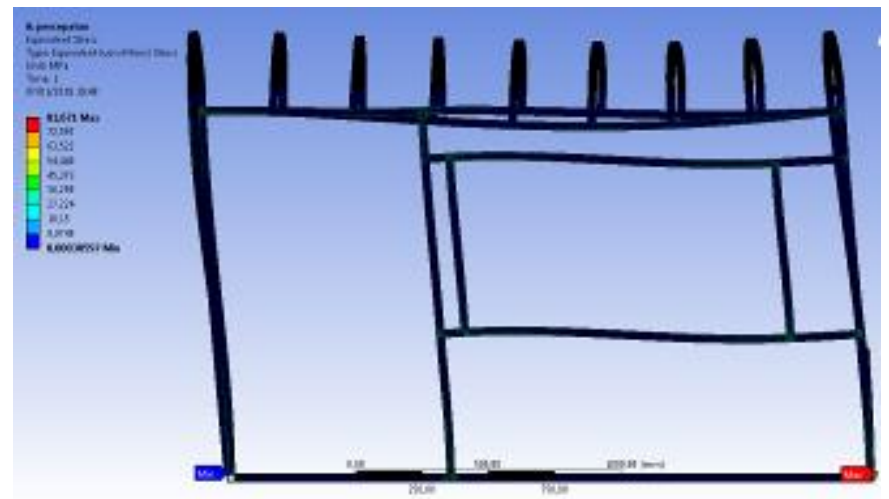

Gambar 12. Hasil simulasi pembebanan pada kerangka box body dengan efek pengereman.

Gambar 12 merupakan letak tegangan maksimal pada kerangka box dengan nilai tegangan von-Mises maksimum sebesar 81,671 MPa



Gambar 13.Deformasi pada bagian box bodi mobil.

Perubahan bentuk maksimal yang terjadi pada struktur rangka box adalah sebesar $1,82 \mathrm{~mm}$ dari bentuk awalnya yang ditunjukkan pada daerah berwarna merah pada Gambar 13.

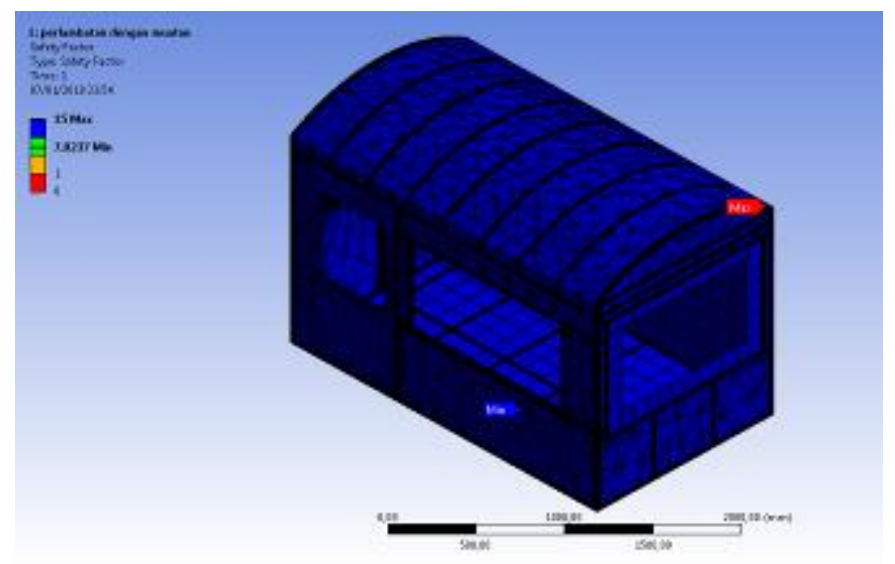

Gambar 14. Safety factor hasil simulasi efek pengereman.

Nilai safety factor maksimum dari hasil simulasi adalah 15 dan minimum 7,02 seperti pada Gambar 14.

c. Saat Mobil dalam Kondisi Belok

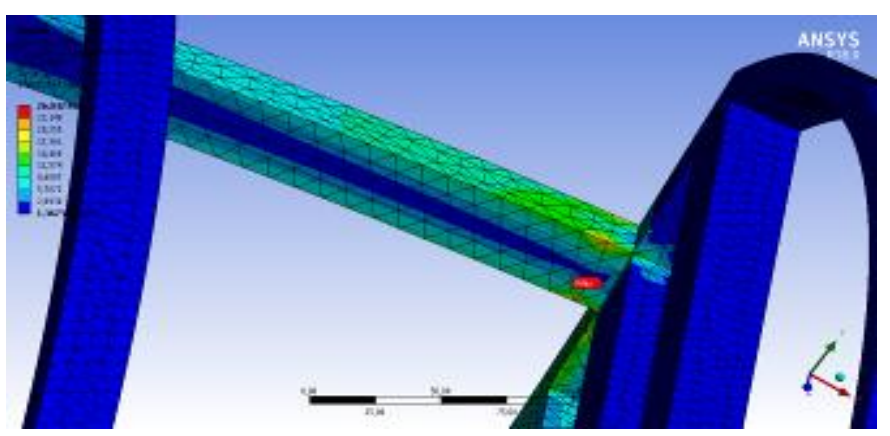

Gambar 15. Detail area yang mengalami stress maksimal pada kerangka dalam kondisi belok

Gambar 15 merupakan letak tegangan maksimal pada kerangka box dengan nilai tegangan von-Mises maksimum sebesar 26,04 MPa. 


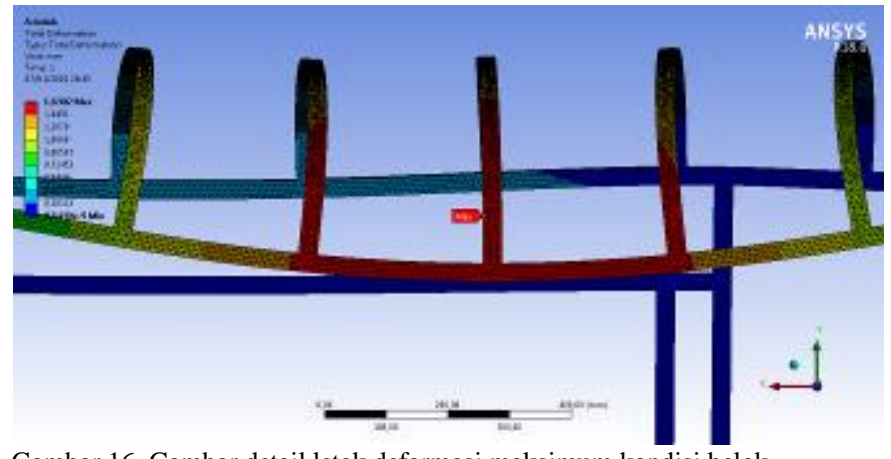

Gambar 16. Gambar detail letak deformasi maksimum kondisi belok

Perubahan bentuk maksimal yang terjadi pada struktur rangka box adalah sebesar $1,63 \mathrm{~mm}$ dari bentuk awalnya yang ditunjukkan pada daerah berwarna merah pada Gambar 16.
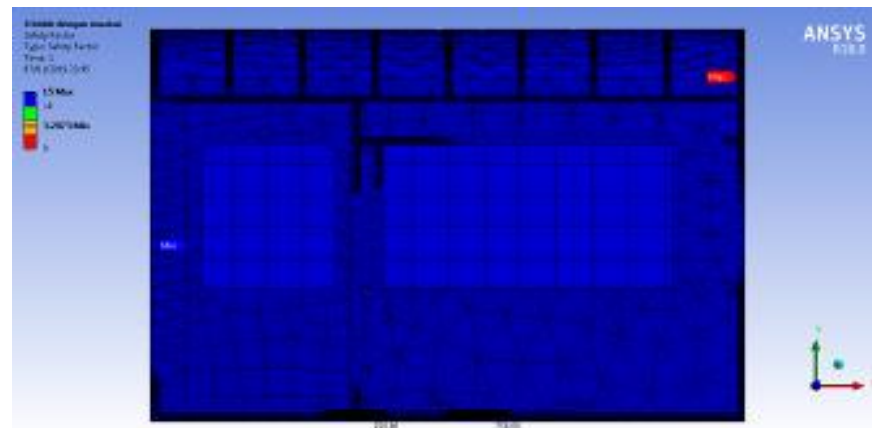

Gambar 17. Safety factor hasil simulasi dalam kondisi belok

Nilai safety factor maksimum dari hasil simulasi adalah 15 dan minimum 3,28 seperti pada Gambar 17.

Setelah diperoleh hasil dari tiap-tiap load case, berikutnya adalah melakukan evaluasi dari hasil yang diperoleh. Hasil dari kelima kondisi yang dianalisa memiliki perbedaan yang signifikan dalam hal safety factor. Dari data tersebut, didapatkan $\sigma_{\text {max won misses }}$ dan angka keamanan dari load case yang telah dilakukan sebagai berikut.

Tabel 4.

Verifikasi keamanan box body terhadap pembebanan

\begin{tabular}{llll}
\hline \hline \multicolumn{1}{c}{ Load case } & $\sigma_{\text {max won misses }}$ & \multicolumn{2}{c}{ Verifikasi keamanan } \\
\hline Percepatan & 87,346 & $\sigma_{\text {stress }}<\sigma_{\text {yield }}$ & Aman \\
Pengereman & 81,671 & $\sigma_{\text {stress }}<\sigma_{\text {yield }}$ & Aman \\
Belok & 26,04 & $\sigma_{\text {stress }}<\sigma_{\text {yield }}$ & Aman \\
\hline \hline
\end{tabular}

Tegangan maksimal yang terjadi dari beban yang didefinisikan dalam beberapa load case pada Tabel 4 di atas adalah 87,346 Mpa yang terjadi ketika mobil mengalami percepatan dengan box tanpa muatan. Sedangkan saat mobil dalam keadaan box muatan penuh tegangan maksimal terjadi ketika berbelok dengan nilai sebesar 67,01. Tegangan ini masih aman dibandingkan dengan tegangan ijinnya. Dari evaluasi hasil simulasi dapat disimpulkan juga bahwa box body ini sudah cukup baik dalam menerima beban.

Tabel 5.

Nilai deformasi maksimum pada setiap kondisi.

\begin{tabular}{ccc}
\hline \hline Load case & $\mathrm{Y}(\mathrm{mm})$ & Titik kritis \\
\hline Percepatan & 5,35 & Bagian atap \\
\hline
\end{tabular}

\begin{tabular}{lll}
\hline Pengereman & 1,82 & Bagian atap sisi kanan \\
Belok & 1,63 & Bagian atap sisi kanan \\
\hline
\end{tabular}

Deformasi maksimal yang terjadi dari beban yang didefinisikan dalam beberapa load case pada Tabel 5 di atas adalah $5,85 \mathrm{~mm}$ yang terjadi ketika mobil mengalami percepatan

Tabel 6.

Nilai safety factor.

\begin{tabular}{ll} 
& Safety factor \\
\hline \hline Load case & 3,034 \\
\hline Percepatan & 7,02 \\
Pengereman & 3,28 \\
Belok & \\
\hline
\end{tabular}

Tabel 6 menunjukkan nilai safety factor untuk masingmasing kondisi dengan box bermuatan penuh, nilai safety factor yang lebih dari 2 menunjukkan bahwa redesign mobil pickup multiguna pedesaan ini dapat dikatakan aman dan baik

\section{KESIMPULAN}

Dari hasil analisa yang telah dilakukan, didapatkan kesimpulan sebagai berikut:

1. Massa total untuk redesign body box sebesar $379,14 \mathrm{~kg}$. Sedangkan massa box body kedua sebesar $415 \mathrm{~kg}$. Dengan pergantian material di beberapa bagian ini mengakibatkan penurunan massa. Penurunan massa yang terjadi yaitu sebesar $36 \mathrm{~kg}$ atau sekitar $8,65 \%$

2. Saat mobil pickup multiguna pedesaan mengalami efek percepatan pada lintasan datar diperoleh nilai Von Mises stress maksimum yang terjadi sebesar $87,346 \mathrm{MPa}$, nilai total deformation maksimum sebesar $5,35 \mathrm{~mm}$ dengan safety factor 3,034

3. Saat mobil pickup multiguna pedesaan mengalami efek pengereman pada lintasan datar diperoleh nilai Von Mises stress maksimum yang terjadi sebesar $81,671 \mathrm{MPa}$, nilai total deformation maksimum sebesar $1,82 \mathrm{~mm}$ dengan safety factor 7,02

4. Saat melewati lintasan belok atau menerima curve resistance dengan radius lengkung minimum yaitu $14,33 \mathrm{~m}$ diperoleh nilai Von Mises stress maksimum yang terjadi sebesar 26,04 Mpa, nilai total deformation maksimum sebesar 1,63 mm dengan safety factor 3,28.

5. Dari analisis dan verifikasi hasil uji terhadap persyaratan desain, box body mobil pickup multiguna pedesaan yang sudah dirancang dapat dinyatakan memenuhi kelayakan keamanan.

\section{DAFTAR PUSTAKA}

[1] B. S.I. Nyoman., Sampurno, Teknologi Otomotif Edisi Kedua. Guna Widya, 2010.

[2] Moretti and et al, Polycarbonate dari International Polymer Solutions. 2013.

[3] J. Brown and A. Robertson, "Motor Vehicle Structures: Concepts and Fundamentals."

[4] R. Juvinall, Engineering Consideration of Stress, Strain, and Strength. USA: Mc Graw Hill, 1967.

[5] ANSYS, “ANSYS help 19.1.Element," USA. 
[6] D. J. Brunelle and M. R. Korn, Advances in Polycarbonates. Washington D.C., 2005. 